\title{
الرسوب وعلاقته بالدافعية للتعلم لدى طلبة الثالث متوسط
}

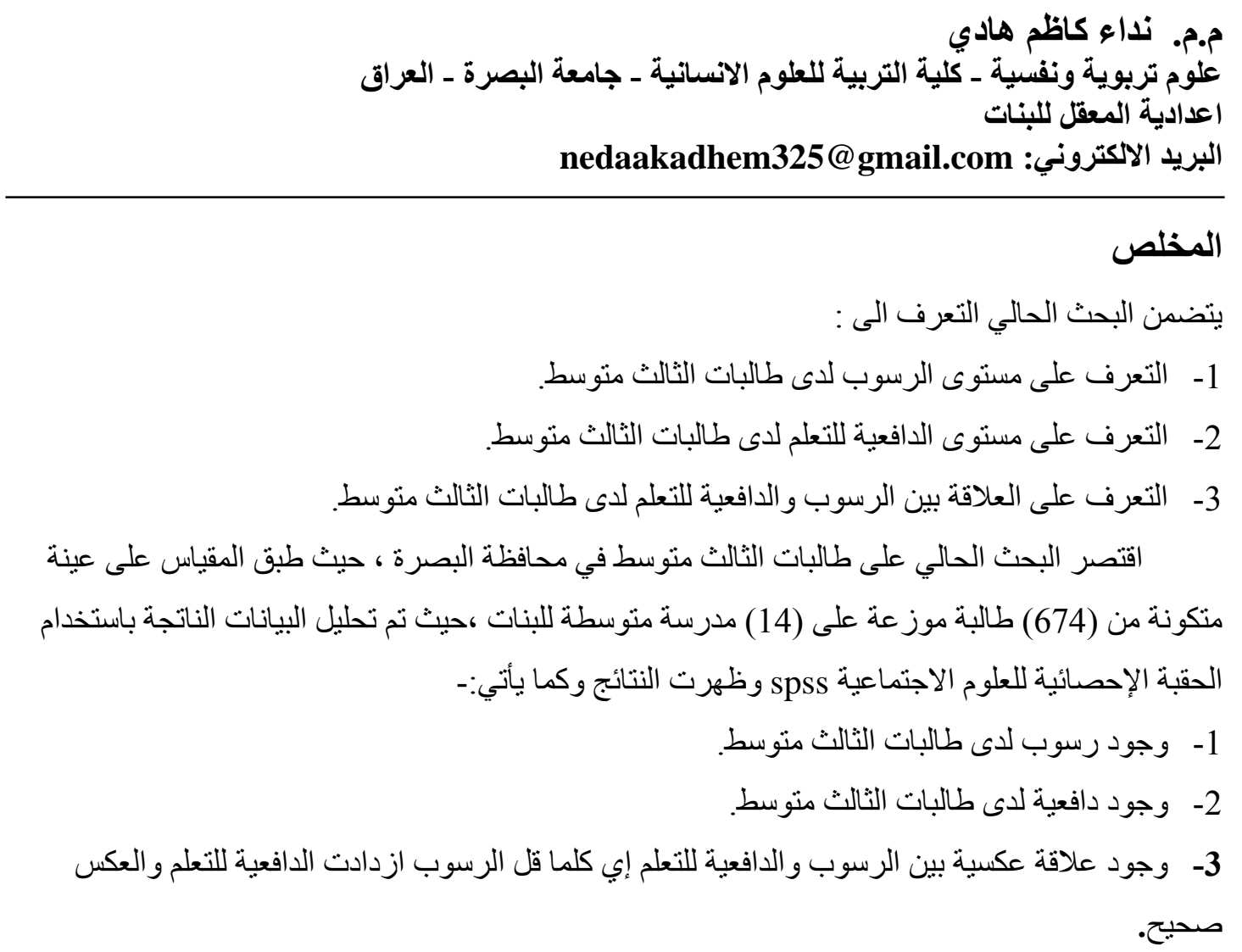

الكلمات المفتاحية: الرسوب، دافعية، تعليم، طلبة، تربوب. 


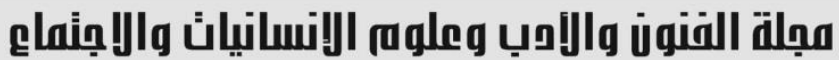

Journal of Arts, Literature, Humanities and Social Sciences

www.jalhss.com

\section{Failure and its Relationship to Motivation for Third Stage Students}

\author{
Assist. lect. Nidaa Kazem Hadi \\ Educational and Psychological Sciences - College of Education for Human Sciences \\ University of Basra - Iraq \\ Al-Maqal Preparatory School for Girls \\ Email: nedaakadhem325@gmail.com
}

\begin{abstract}
ABSTACT
Current research includes learning about:

.1-Knowing the failure level of female students of the third year average

.2-Knowing the level of motivation for learning among third year students

3-Understanding the relationship between failure and the motivation to learn

.among students of the third average
\end{abstract}

The current research was limited to third intermediate female students in Basra governorate, where the scale was applied to a sample consisting of (674) female students distributed to (14) middle schools for girls, where the resulting data was analyzed using the statistical era of social sciences spss and the results appeared as follows::-

1-There is an average failure of third year students

.2-The presence of motivation among female students of the third average

3-There is an inverse relationship between failure and the motivation to learn,

that is, the less failure, the greater the motivation to learn and vice versa.

Keywords: Failure, Motivation, Education, Students, Educational. 


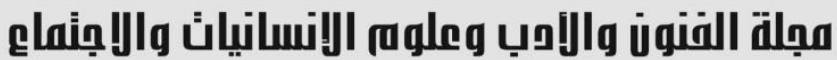

\author{
Journal of Arts, Literature, Humanities and Social Sciences \\ www.jalhss.com
}

\section{المبحث الاول}

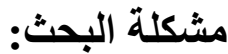

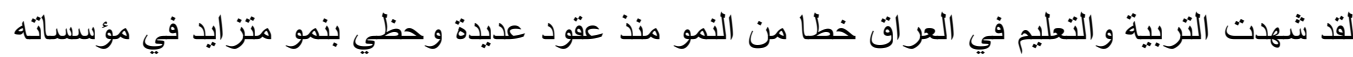

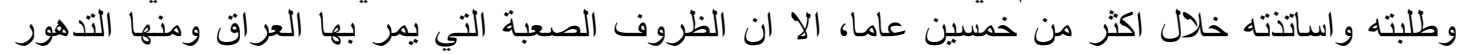

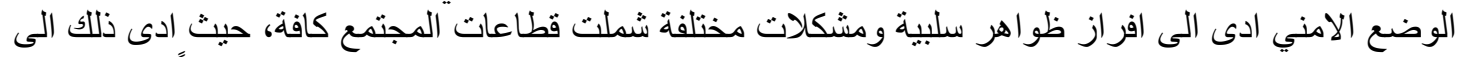

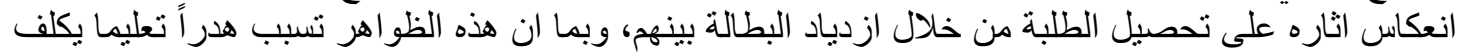

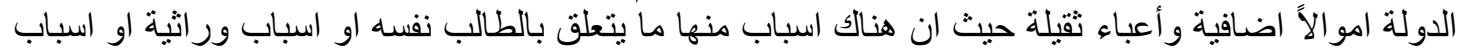
اسرية او اجتماعية او اقتصادية.

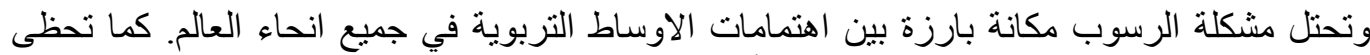

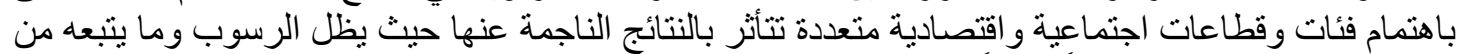

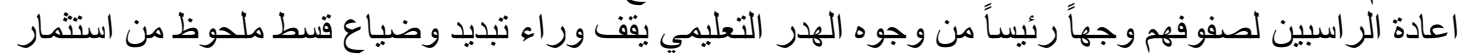

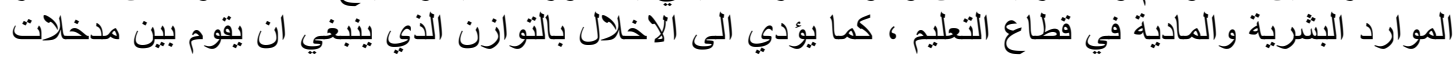

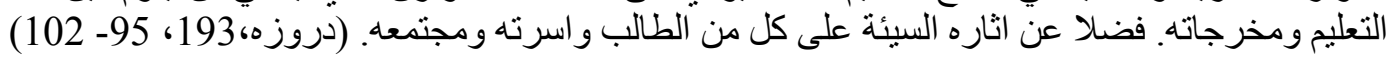

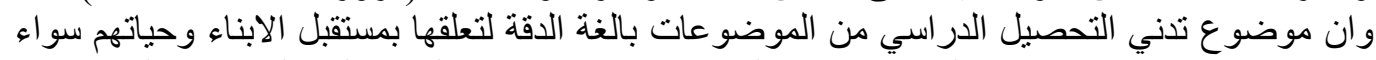

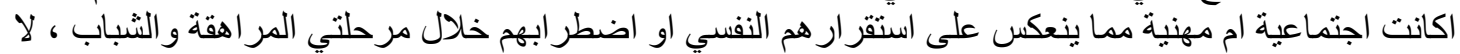

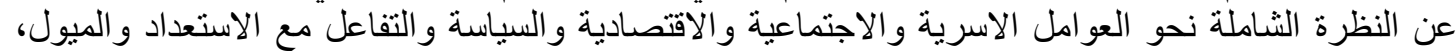

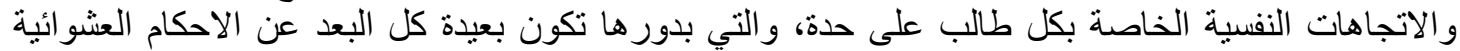

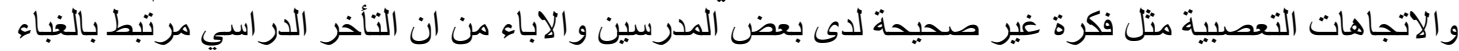

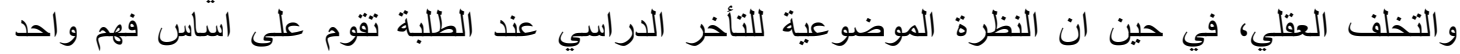

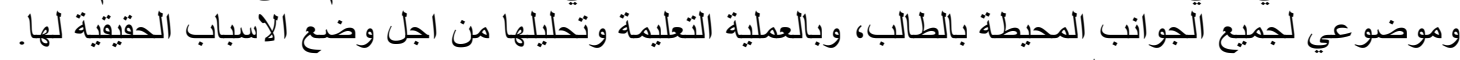

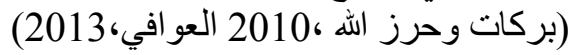

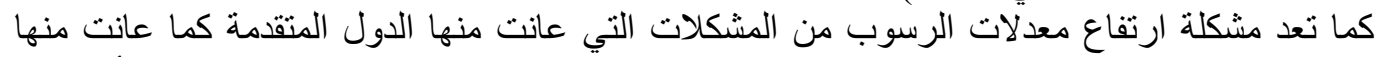

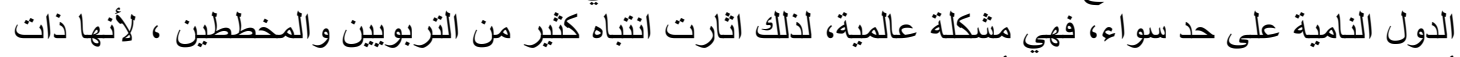

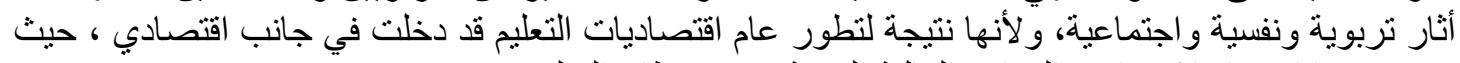

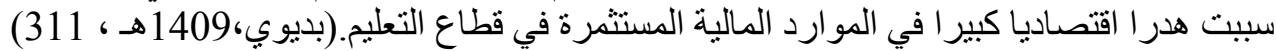

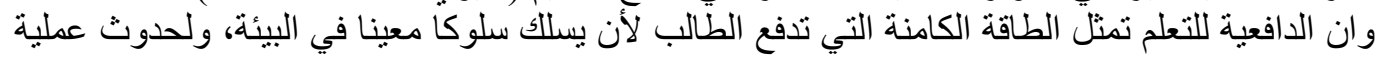

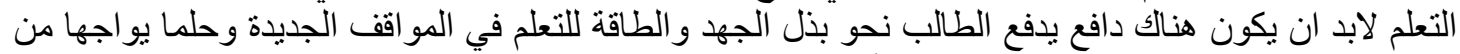

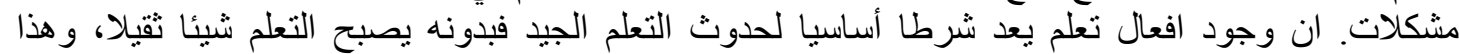

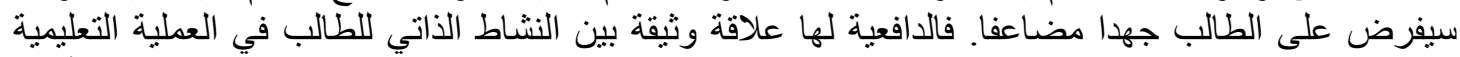

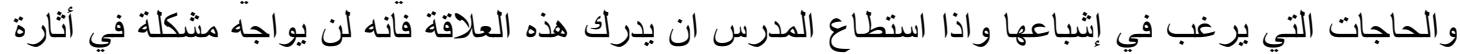

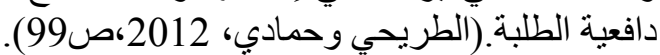

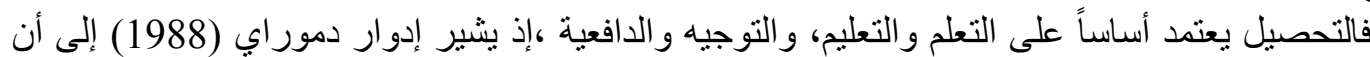

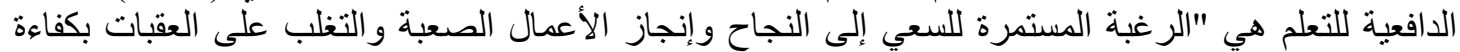

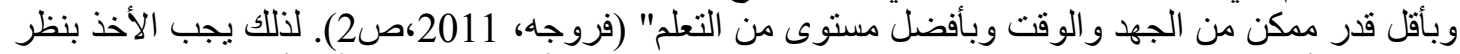

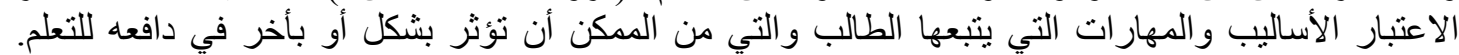

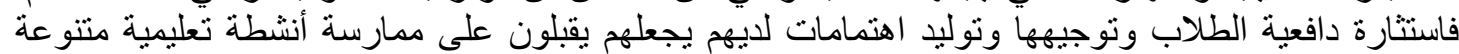
بأداء عالٍ، و التبني طرق فعالة في معالجة المعلومات التي يتعامل معها الطالب في أثناء عملية التحصيل. (حدة، نئة

(4)، 2012

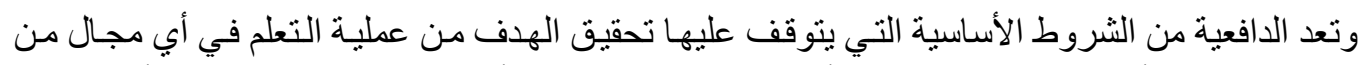

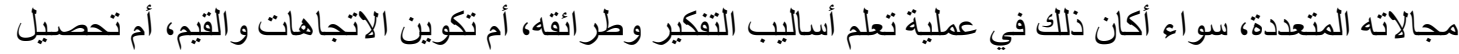

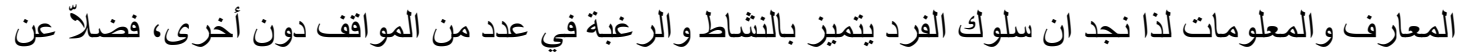




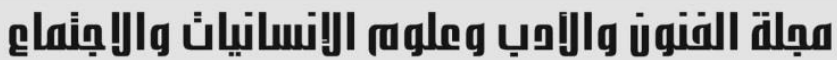

Journal of Arts, Literature, Humanities and Social Sciences www.jalhss.com

أن اهتمامات الفرد قد تكون واضحة في عدد من المو اقف في حين تكون غير واضحة في مو اقف أخرى، وإق وذلك يرجع إلى مستوى دافعية الفرد نحو ممارسة السلوك في هذه المو اقف دون غير ها (الخالدي، 2012، صن فئ 104).

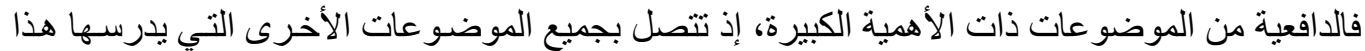

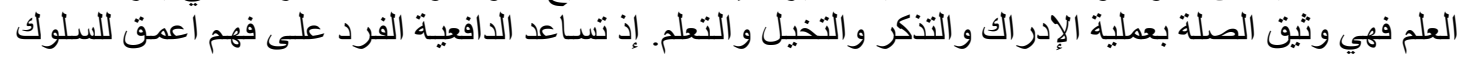

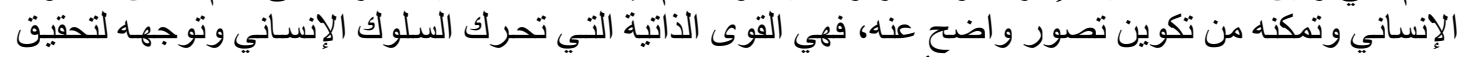

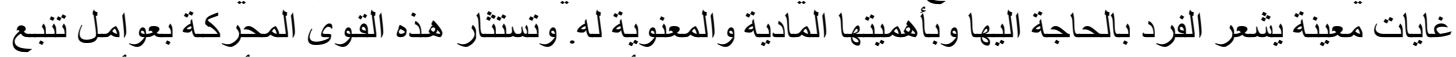

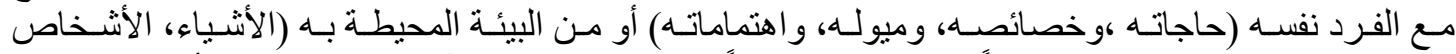

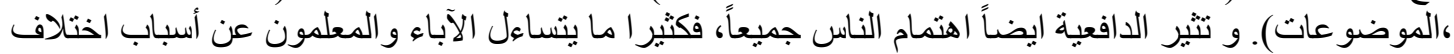

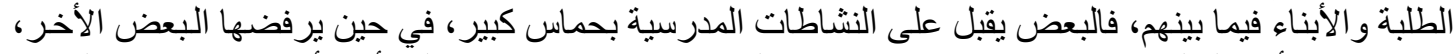

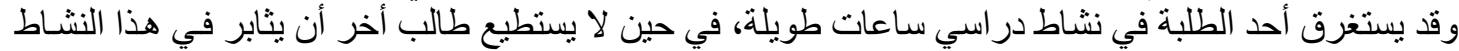

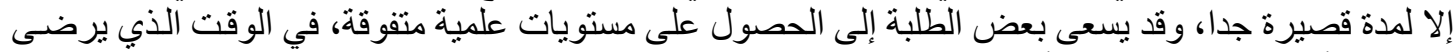

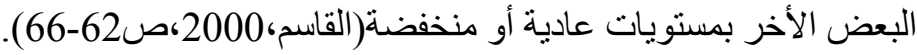

وتسهم الدافعية ايضاً في تسهيل فهينا لبعض الحقائق المحيرة في السلوك الإنساني، ويمكن القول بشكل

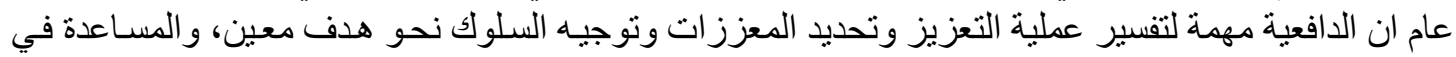

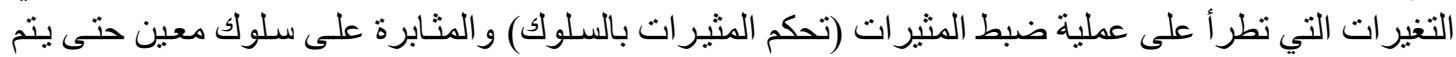
أنجازه، كذلك فأننا نتصرف عادي عادة في أثناء حياتتا اليومية وكأننا نتقام نحو مكان ما (أي أن سلوك الإنسان الإنسان هادف)،

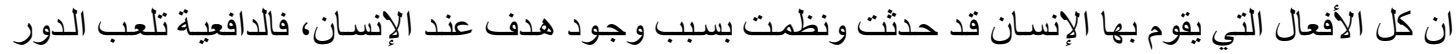

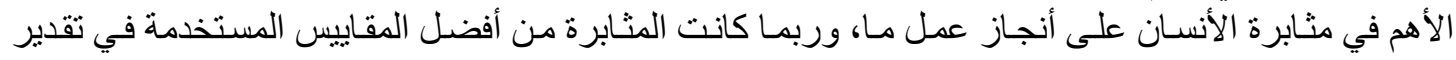

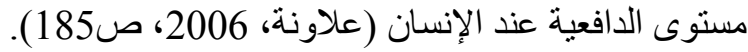

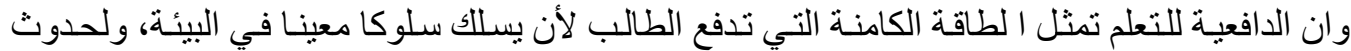

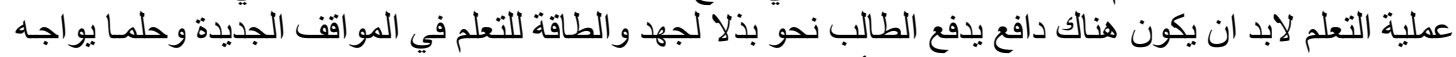

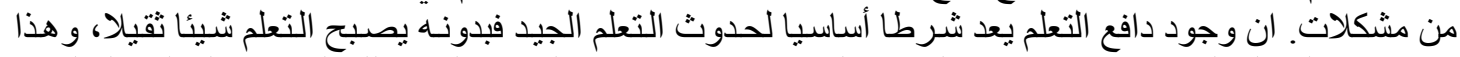

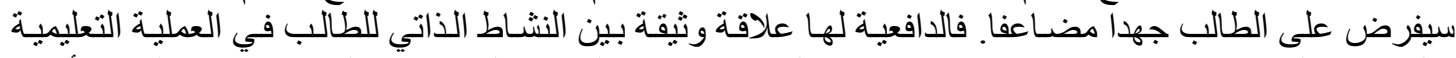

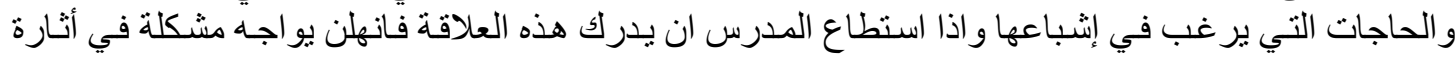

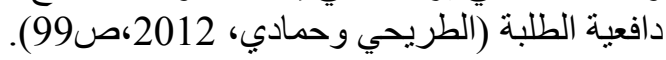

تتمثل حدود البحث: اهداف البحث:

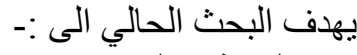
1 - التعرف على مستوى الرسوب لأى طالبات الثالث متوسط.

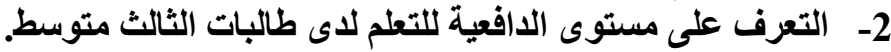
3- التعرف على العلاقة بين الرسوب التوبة والدافعية للتعلم لاى طالبات الثالث متوسط.

1- الرسوب: البقاء في نفس الصف الدراسي لعدم القدرة على اجتباز الامتحان واعادة السنة مرة اخرى .

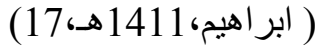

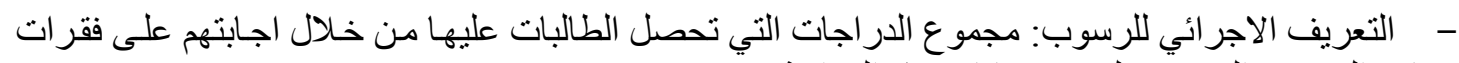

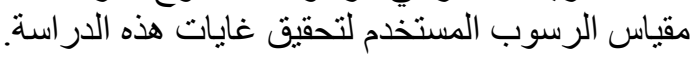

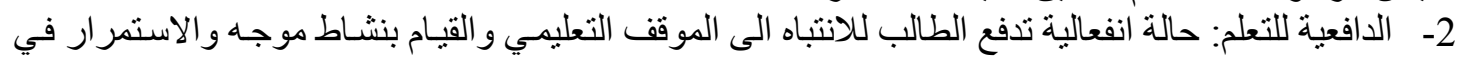

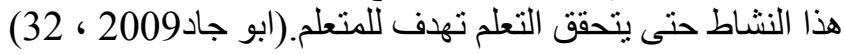




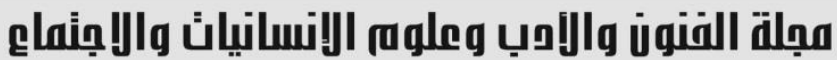

Journal of Arts, Literature, Humanities and Social Sciences www.jalhss.com

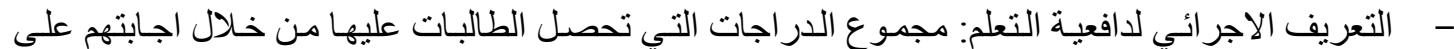

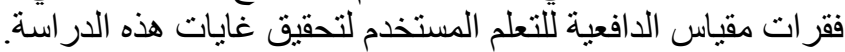

\section{المبحث الثاني \\ الاطار النظري}

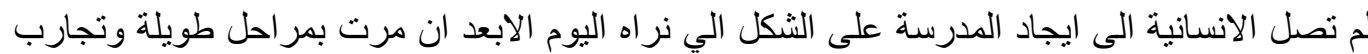

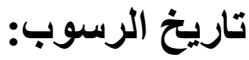

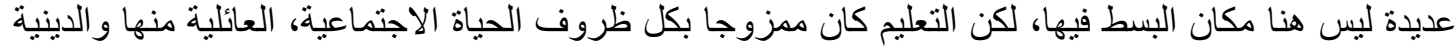

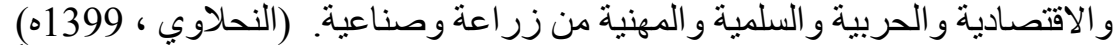

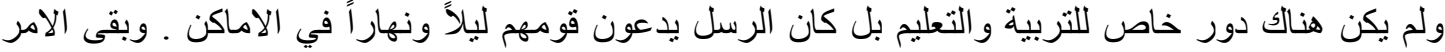

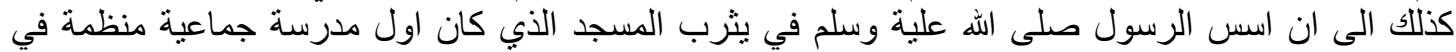

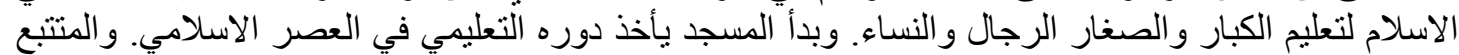

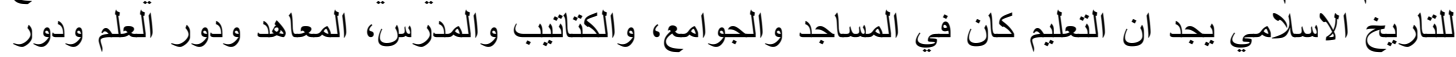

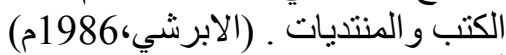

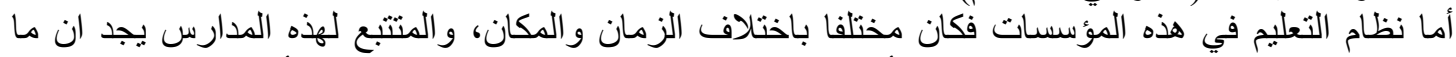

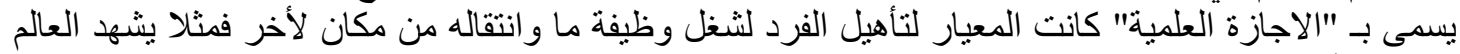

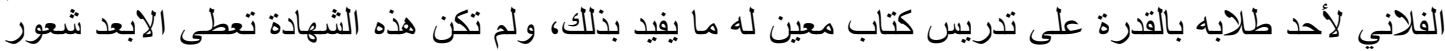

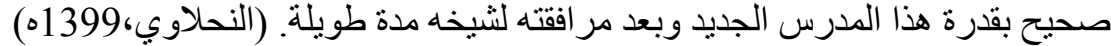

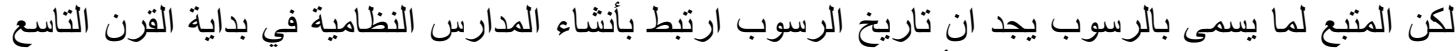

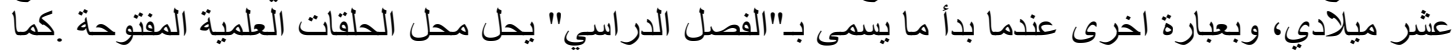

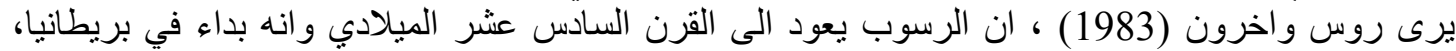

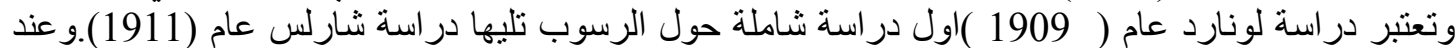

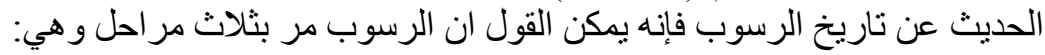

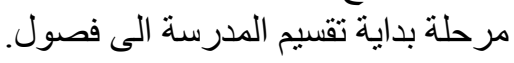
مرحلة النقل الالي.

$$
\text { مرحلة تأسيس معيار لحصول الطالب المهار ات الاساسية. }
$$

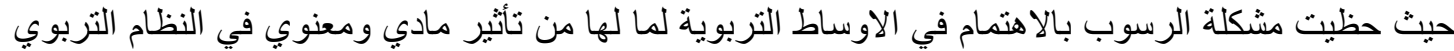

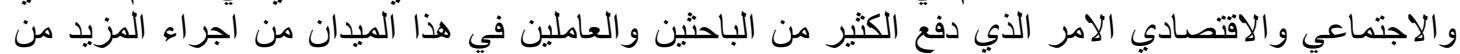

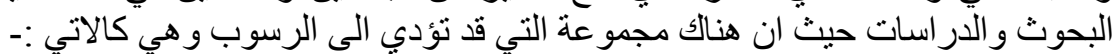

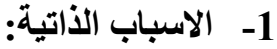

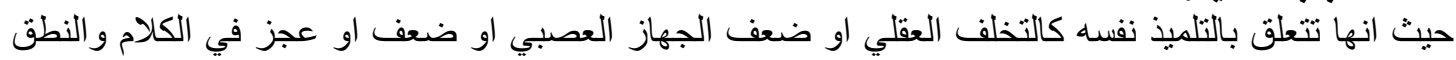
و الخوف و عدم الثقة بالنفس والاصنابة بعاهات وتشوهات جسمانية تشعر التلميذ بالسخرية والاهانة والتي تجعله يهرب من المدرسة.

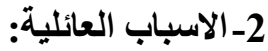
حيث ان للأسرة مساهمة كبيرة في رسوب ابناءهما ويكون ذللك في الحالات الاتبة:

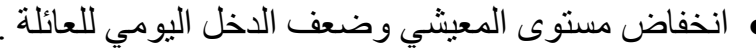

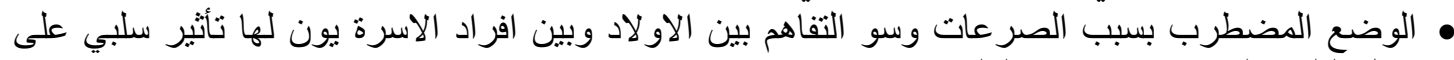
3- الاسبيل التلميذ الدراسي المبري ومردوده العلمي.

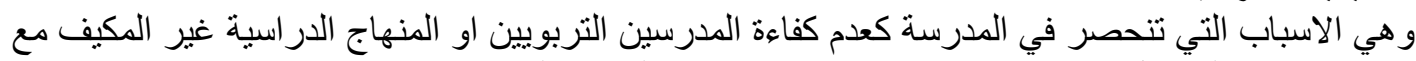

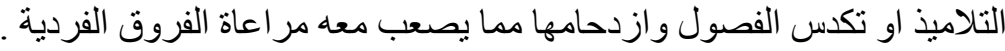

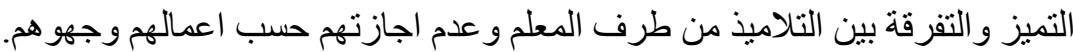

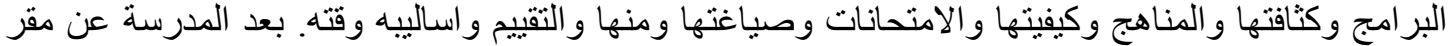
مسكن التلميذ مما يتعبه وير هقه وكذللك صعوبة التتقل اليها مما يؤثر كل ذلك على التحصيل الدر اسي. 


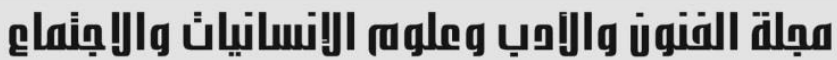

Journal of Arts, Literature, Humanities and Social Sciences www.jalhss.com

Volume (62) December 2020

العدد (62) ديسمبر 2020

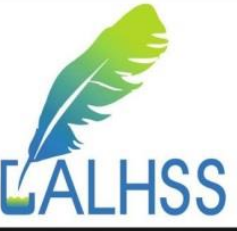

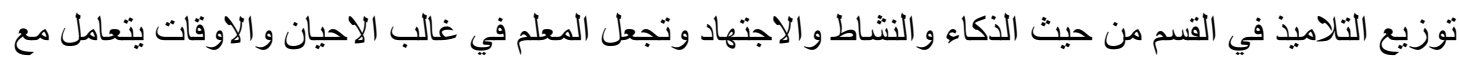

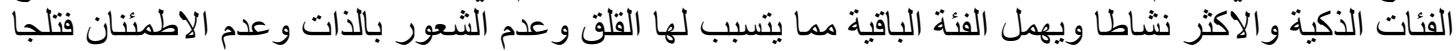

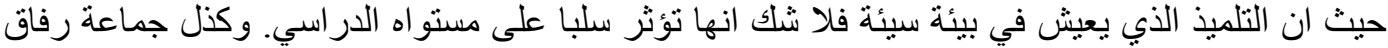

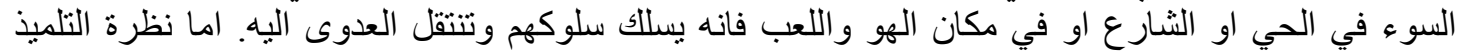

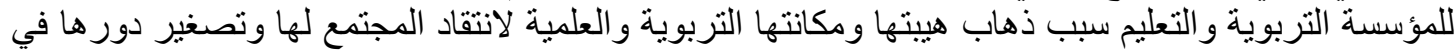

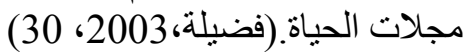

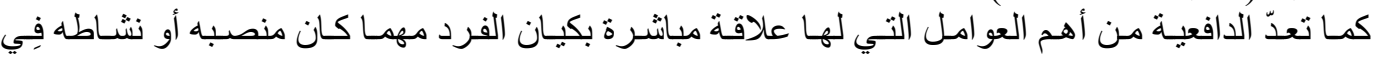

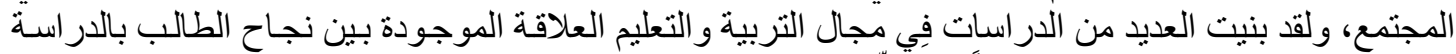

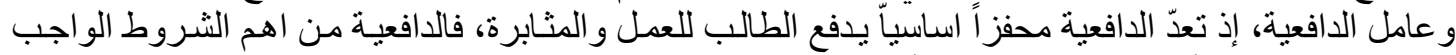

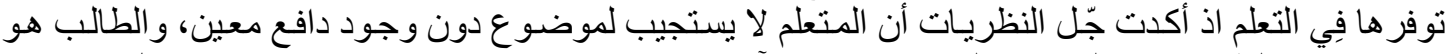

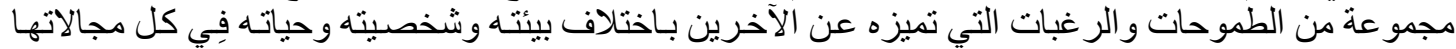

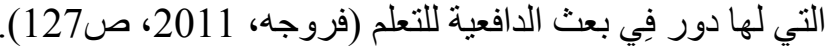

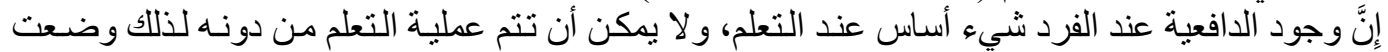

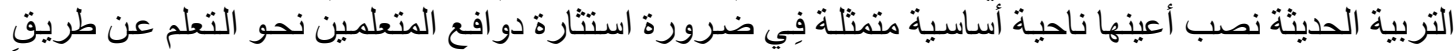

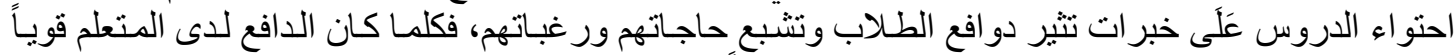

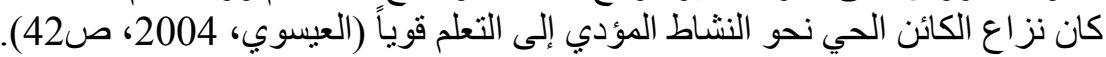

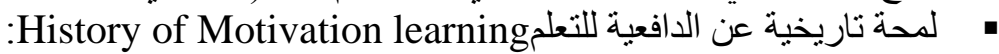

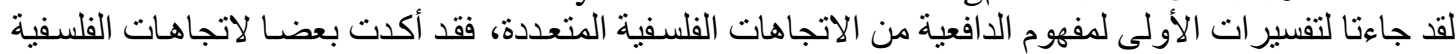

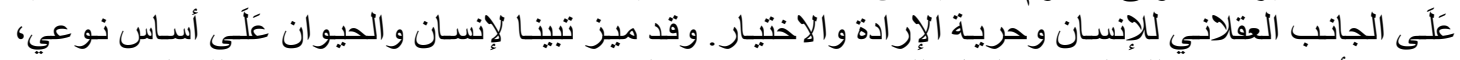

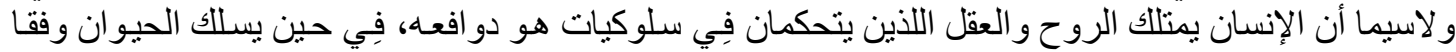

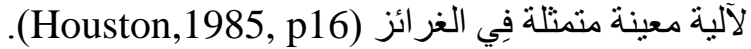

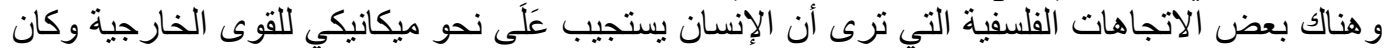

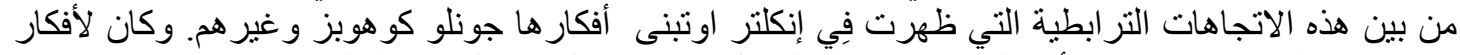

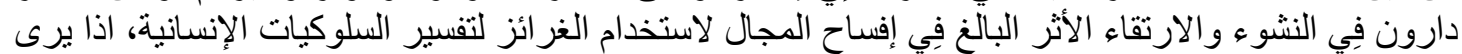

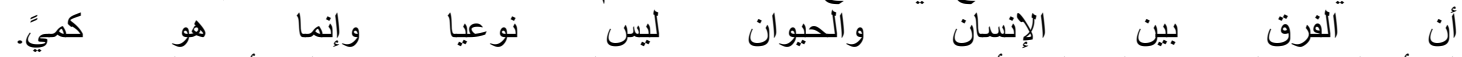

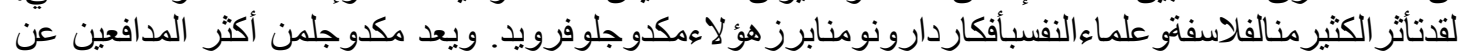

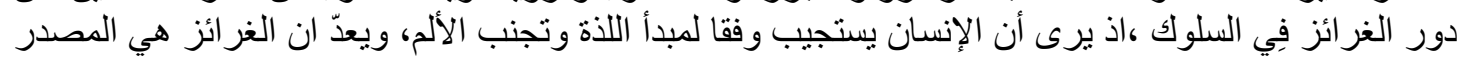

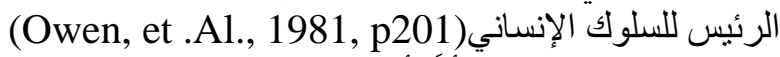

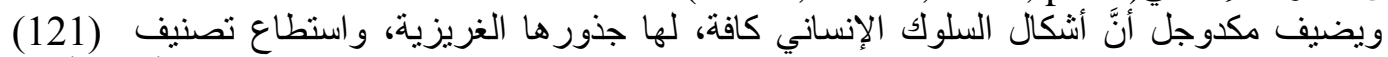

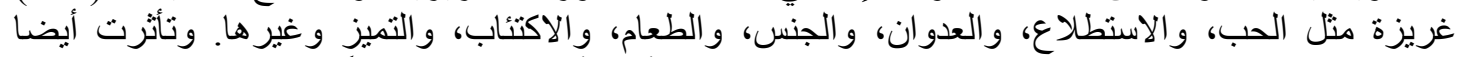

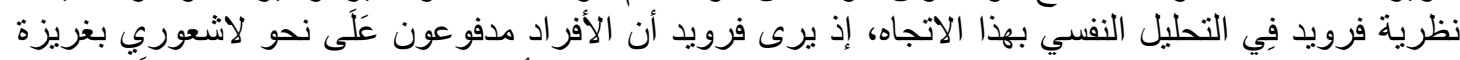

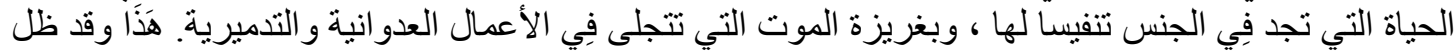

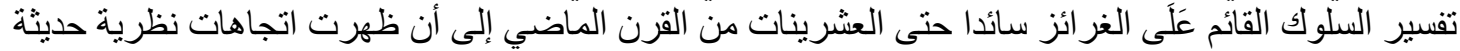

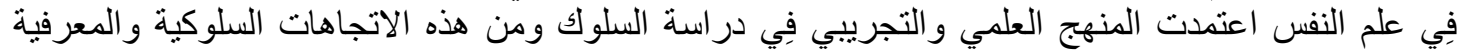

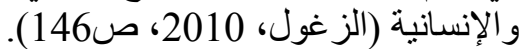

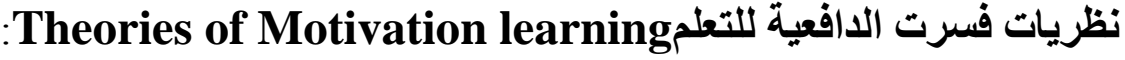

أولا: الاتجاه السلوكي فنيرت الات فعية Behavioral Perspective:

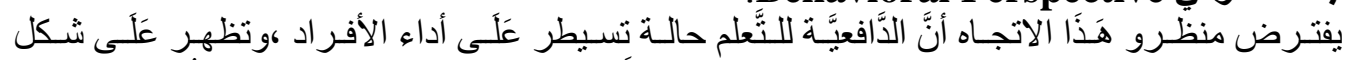

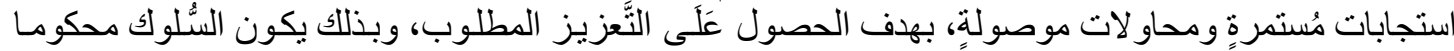

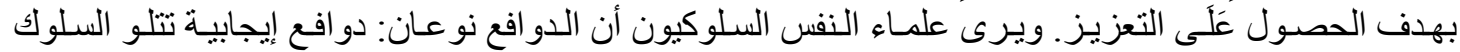

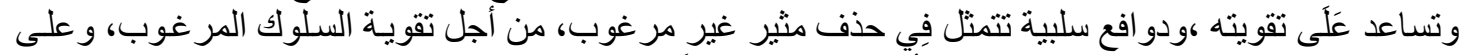

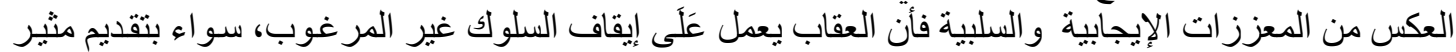




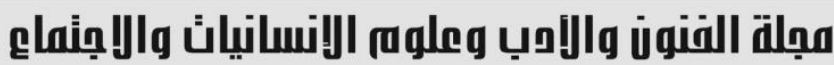 \\ Journal of Arts, Literature, Humanities and Social Sciences www.jalhss.com}

Volume (62) December 2020

العدد (62) ديسمبر 2020

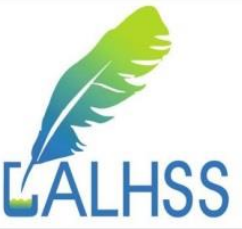

غير محبب أم بحذف مثير محبب، وبرى سكنر أن لاى الفرد حاجات جسمية أساسبة، كالجو ع و العطش، تحتـاج

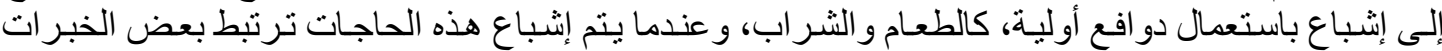

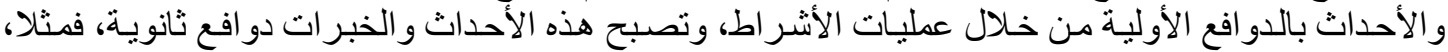

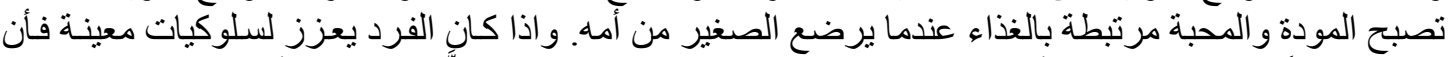

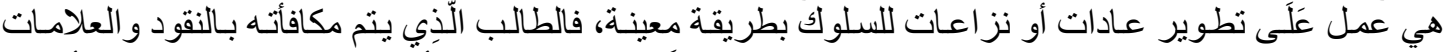

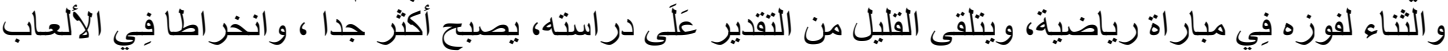

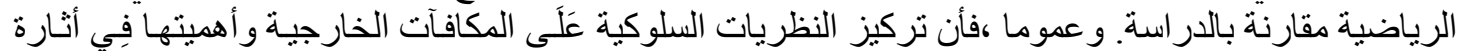

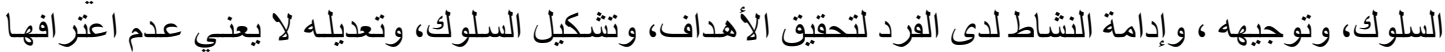

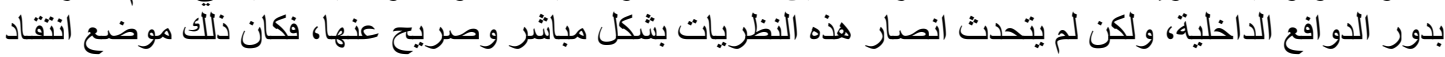

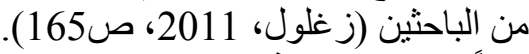

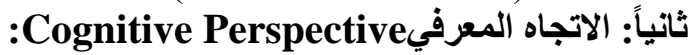

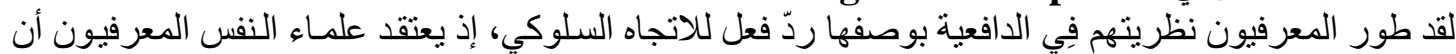

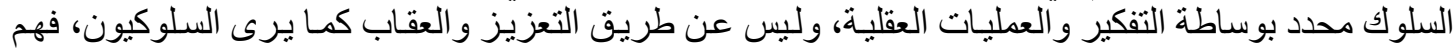

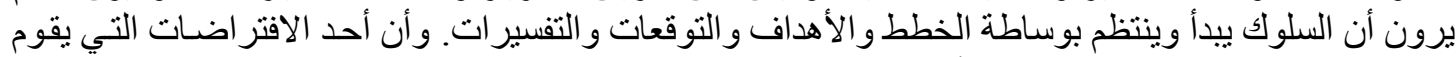

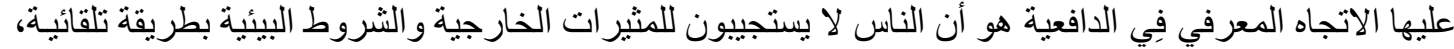

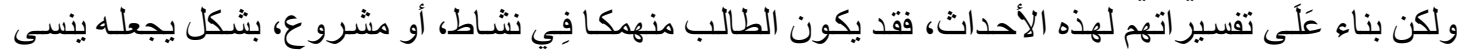

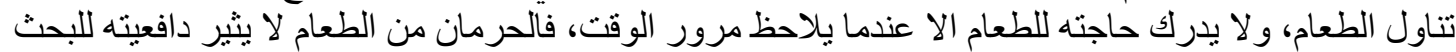

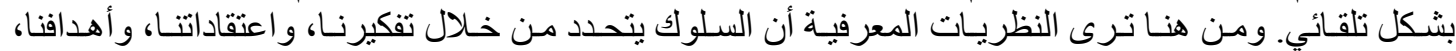

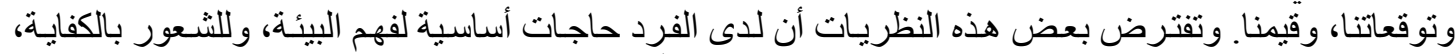

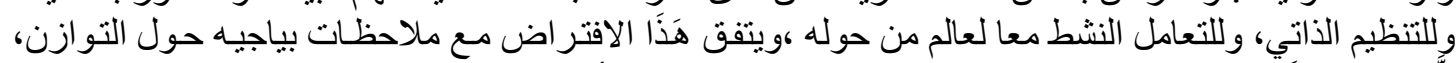

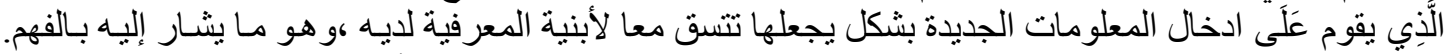

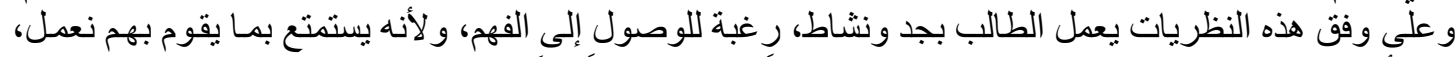

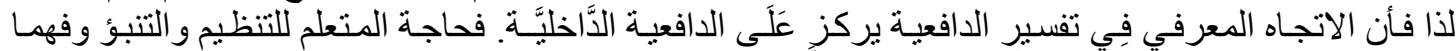

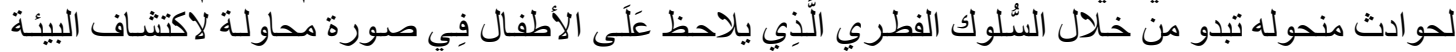

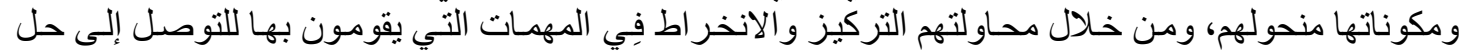

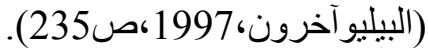

ثُالثاً: الاتجاه الإنساني Humanistic Perspective

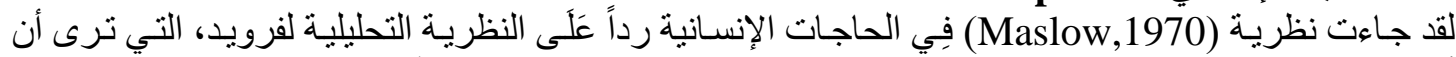

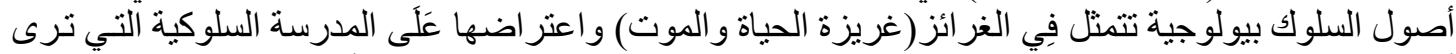

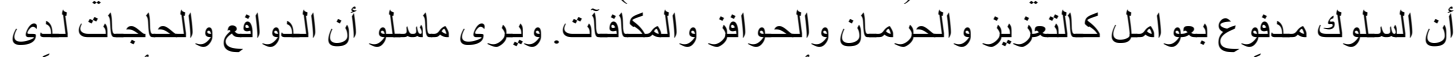

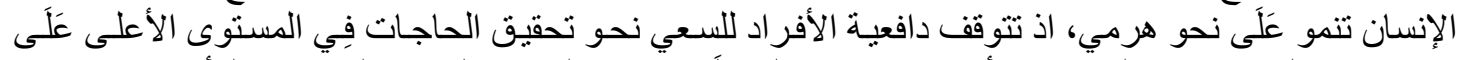

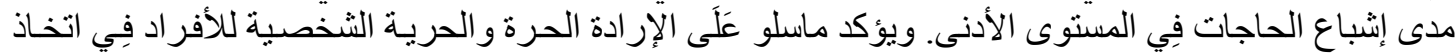

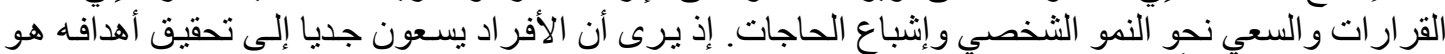

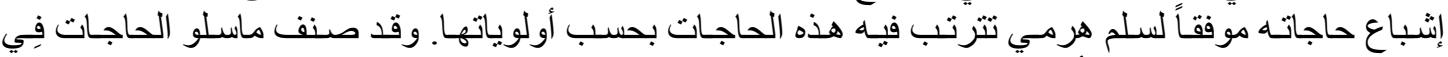

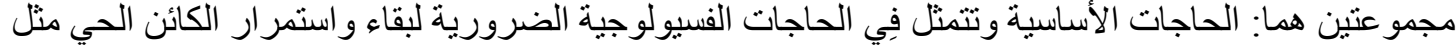

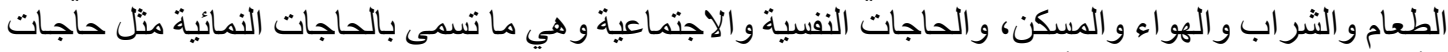

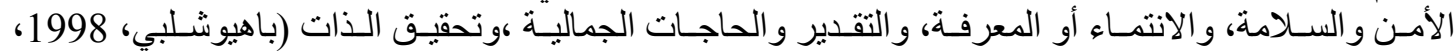

رابعاً: الاتجاه المعرفي الاجتماعي Cognitive Social Perspective:

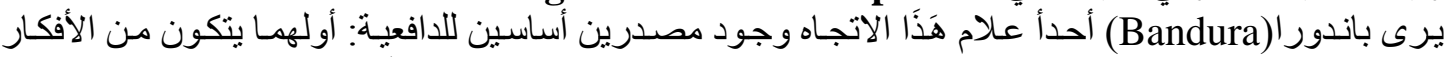

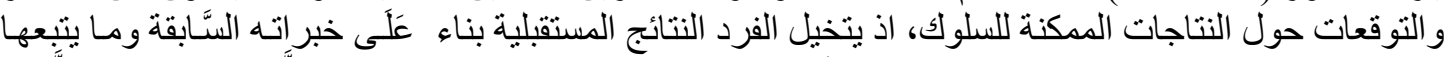

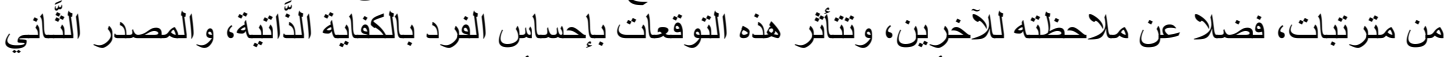

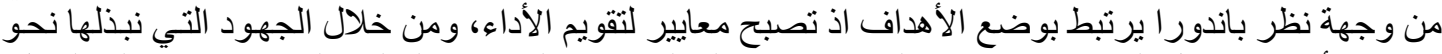

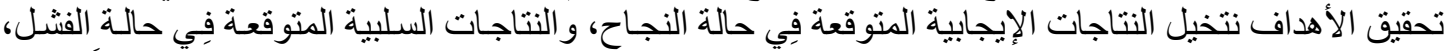

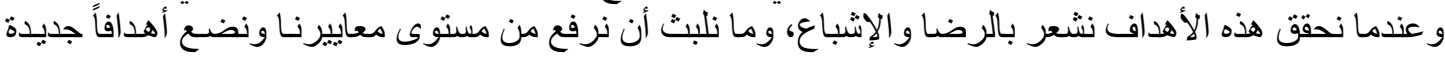




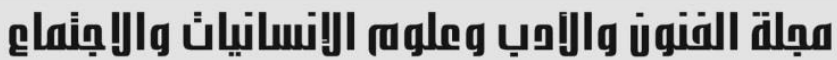

Journal of Arts, Literature, Humanities and Social Sciences www.jalhss.com

.(Woolfolk, 1987, P267)

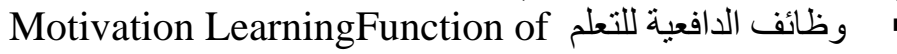

أولا: الوظيفة الاستثارية: Arousal Function:

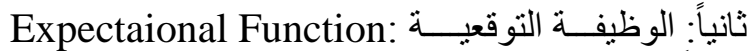

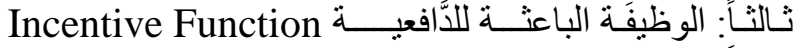

رابعاً: الوظيفة العقابية أو التهذيبية Punitive Function

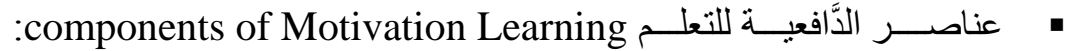

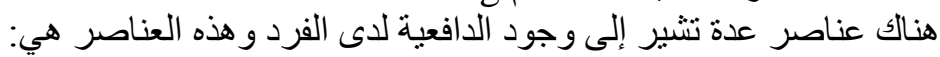

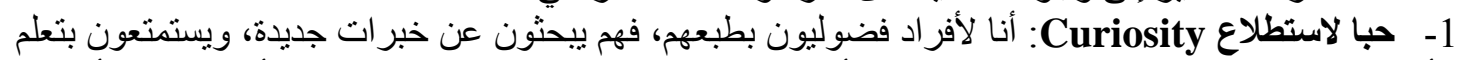

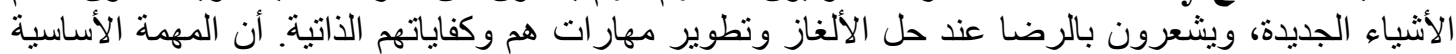

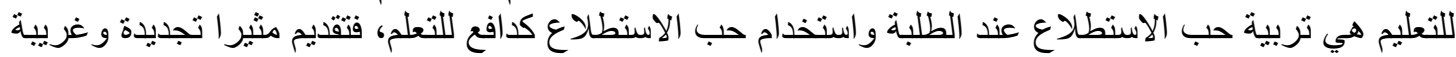

للطلبة يستثير حب الاستطلاع لديهم(Connie, 1997, p2).

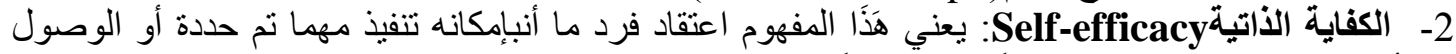

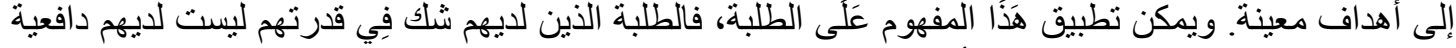

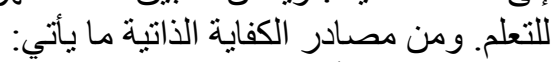

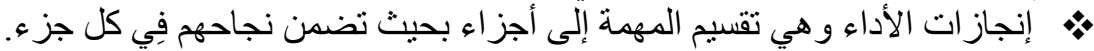

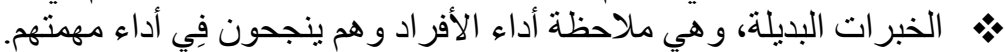

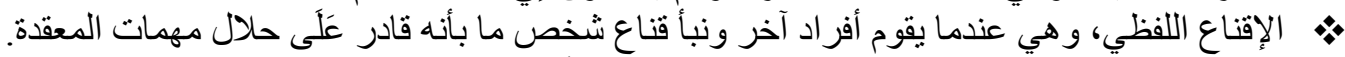

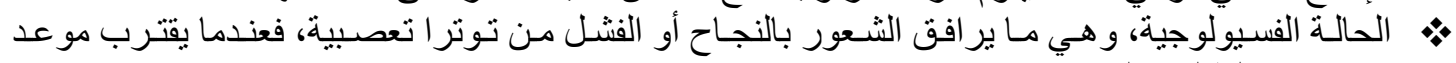

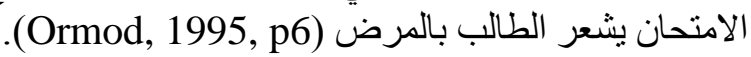

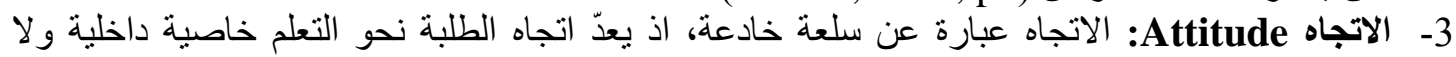

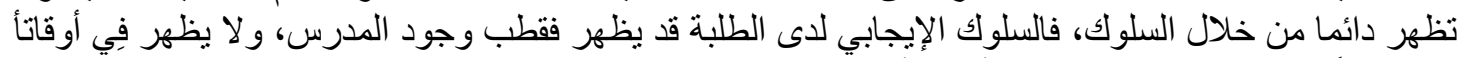

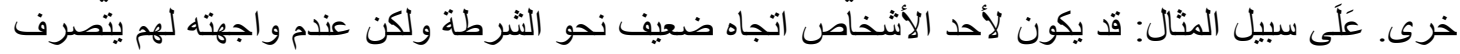

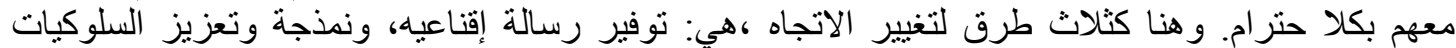

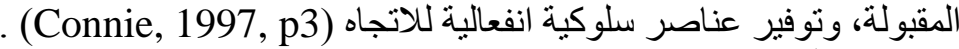
4- الحاجة Need: يعرف مورفي (Murphy, 1947) الحاجة بانها الثعور بنقص شيء معين، اذا ما وجدت حقق الإشباع (Murphy, 1947 , p200).

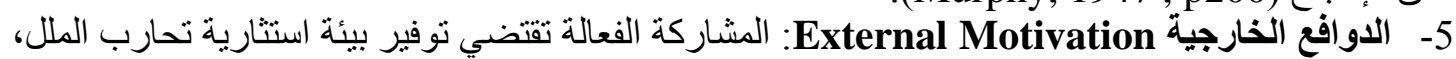

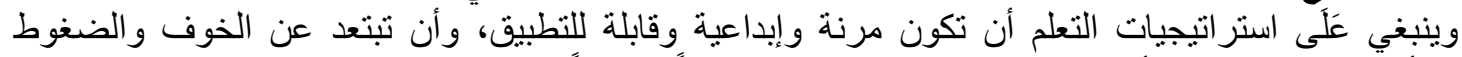

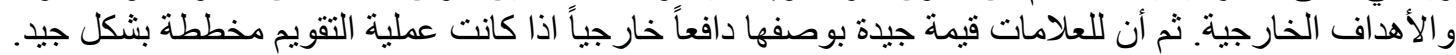

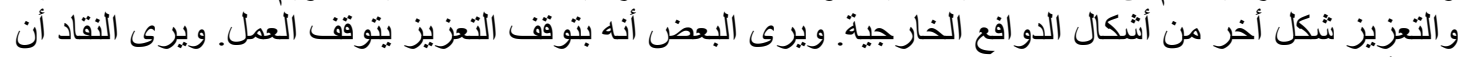

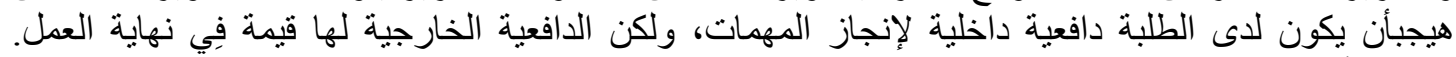

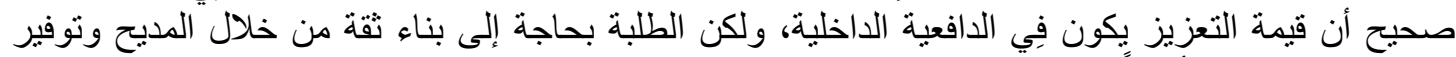

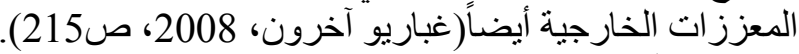

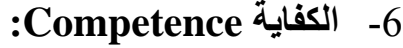

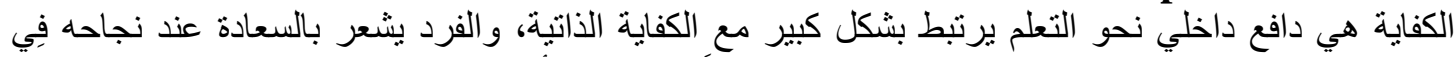

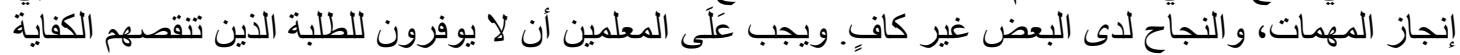

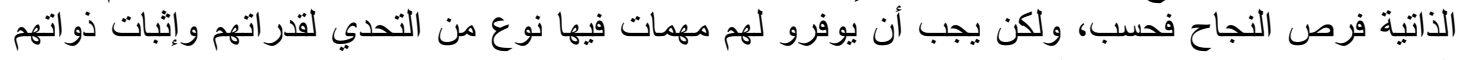

(Wlodkowski, 1991, p2)

7- الحافز Incentive: يعرف ماركس الحافز بأنه تكوين فرضي بستخدم للإشارة إلى العمليات الدافعة

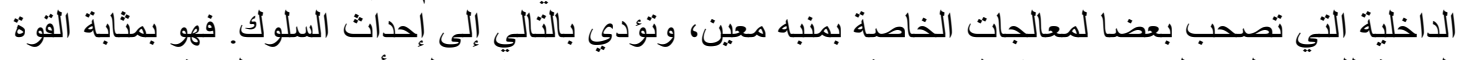

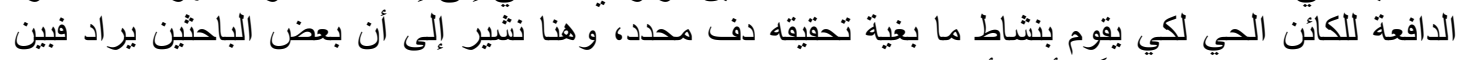

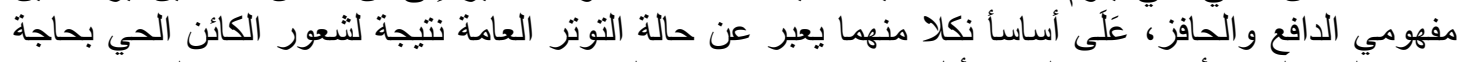

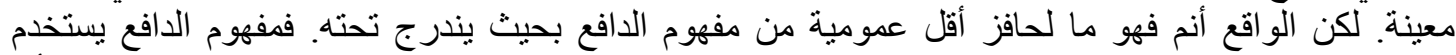

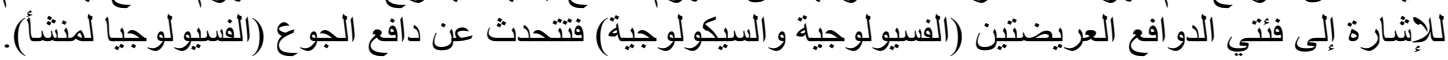




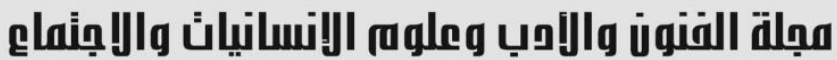

Journal of Arts, Literature, Humanities and Social Sciences www.jalhss.com

ودافع الإنجاز (السيكولوجيا لمنشأ) في حين تثير الحو افز إلى الدوافع الفسيولوجية المنشأ فقط، وهو ما تعبر عنها

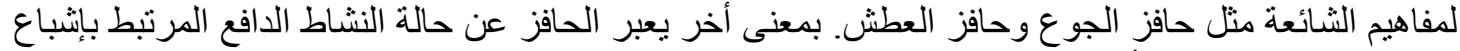
حاجات فسيولوجية المنشأ فقط (Wlodkowski, 1991, p2).

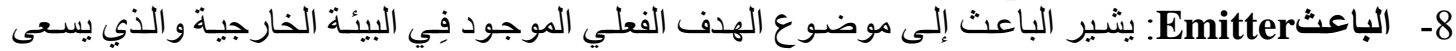

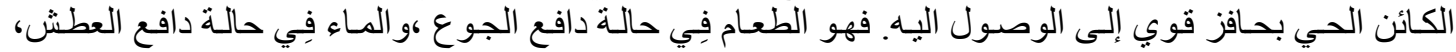
و النجاح و الثهرة فِي حالة دو افع الإنجاز (Wlodkowski, 1991, p2).

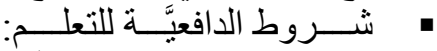

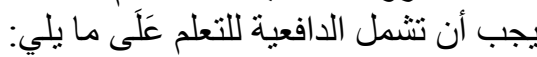

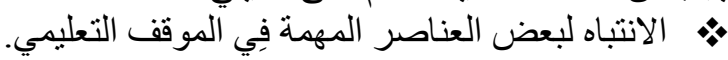

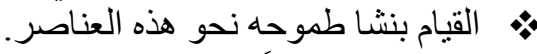

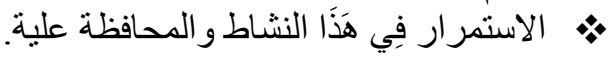

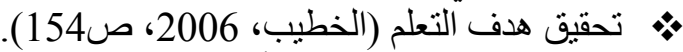

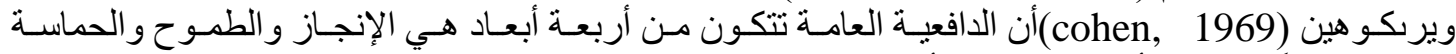
و الإصر ار عَلَى تحقيقا لأهداف المرجوة أي المثابرة (cohen, 1969, p18).

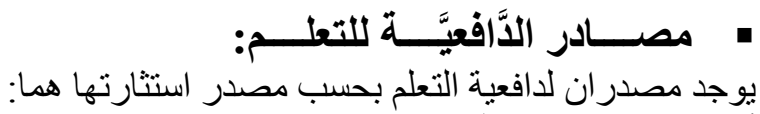

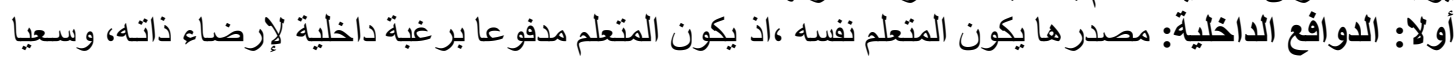

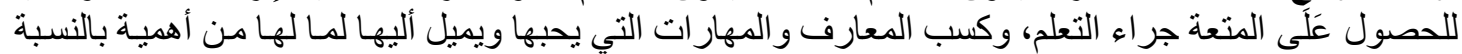

ثثانياً: الدوافع الخارجية: مصدر ها خارجي، فقد يدفع المتعلم للتعلم إرضـاء للمعلم أو الو الدين (غباري، 2008،

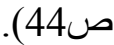

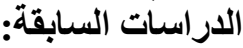
1- دراسة فضيلة(2013) بعنوان(الرسوب المدرسي في التعليم المتوسط والثانوي في بلاية وهران خلال (الفترة (2005-2006، 2009- 2010) (2010)

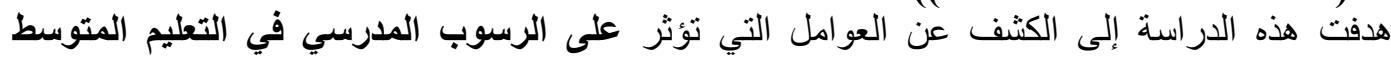

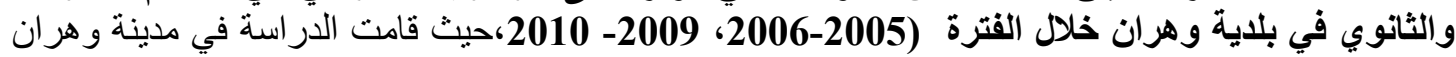

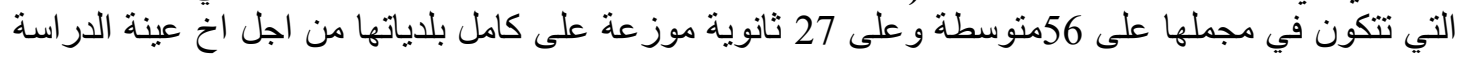
موضوع الرسوب المدرسي حيث كانت النتائج لاتي:

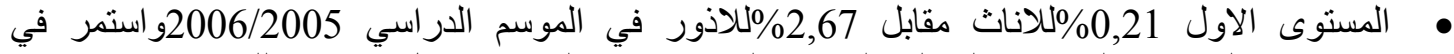

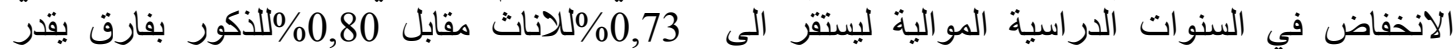
ب0,52\% بلانات و 1,87\% للأكور .

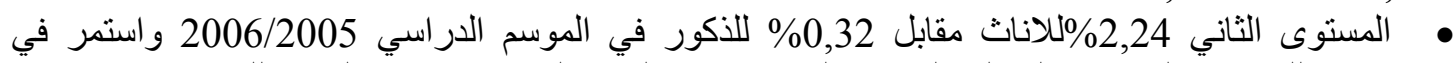

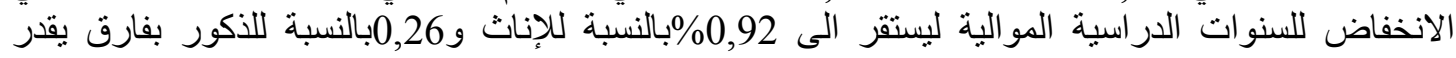

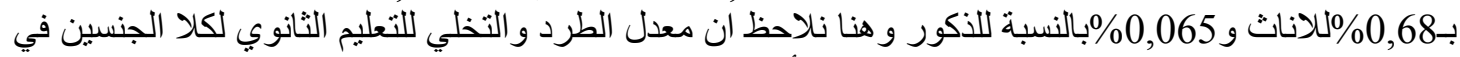

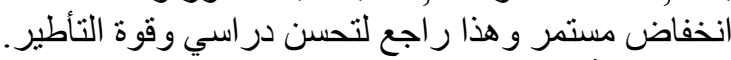
2- دراسة خميس (ب، ت) بعنوان: (التفكير الإبداعي وعلاقتهله بدافعية التعلم لاى طالبات بعض كليات جامعة

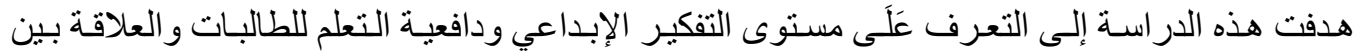

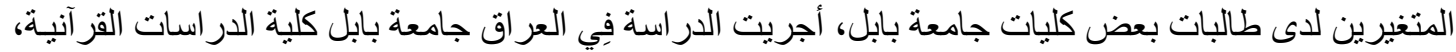

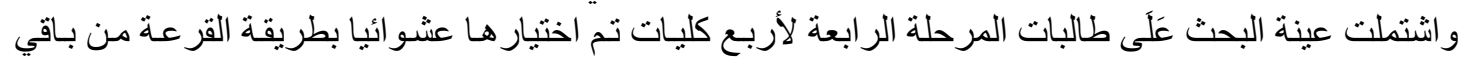

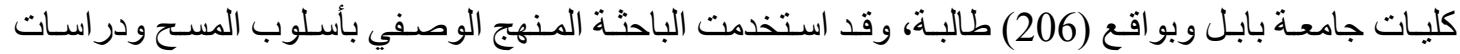
المقارنة و الدر اسات الارتباطية لملاءمته لطبيعة مشكلة البحث وأهدافه، وقد اعتمدت فِي قياس الدافعية للتعلم عَلَى بالى 


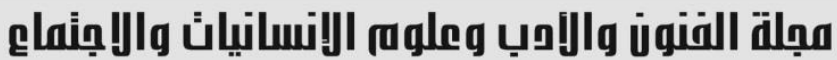

Journal of Arts, Literature, Humanities and Social Sciences www.jalhss.com

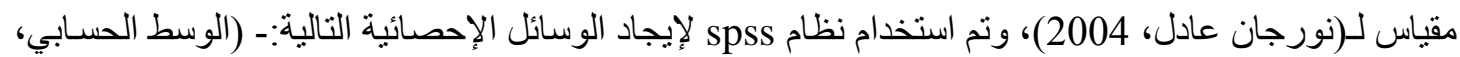

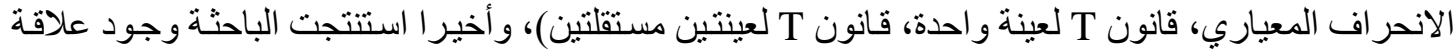

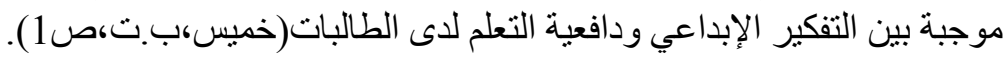

\section{المبحث الثالث \\ منهجية البحث الباث}

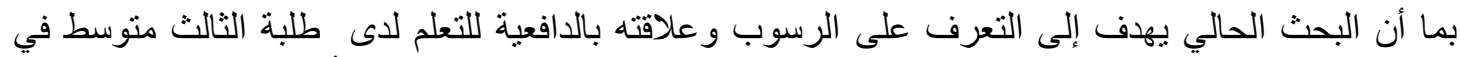

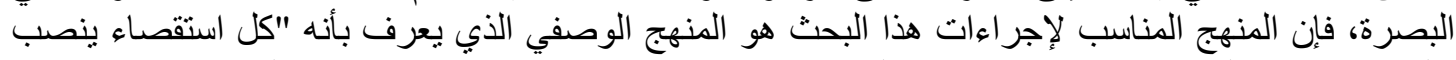

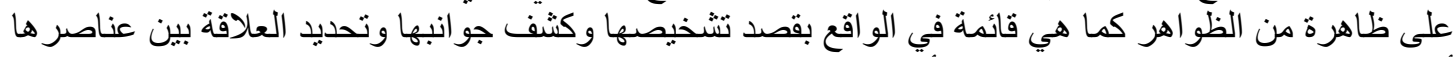
أو بينهاو بين ظو اهر تعليمية واجتماعية أخرى في الفي (فاندالين، 1994 293:).

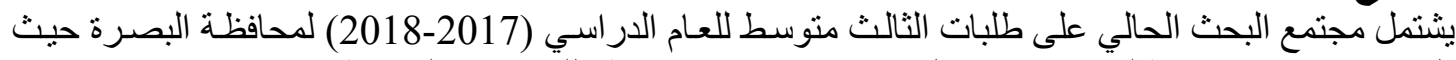
بلغ عددهم (13484) طالبة موز عين على على (118) مدرسة متوسطة للبنات من المحافظة عينة التطبيق : عارديق

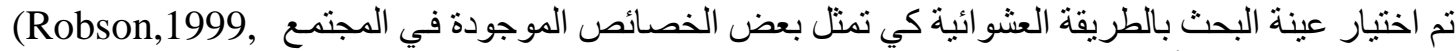
(P138) إذا بلغ عدد أفر اد العينة (674) طالبة وموز عين على (14) مدرسة متوسطة للبنات.

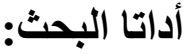

دن أجل تحقيق أهداف البحث الحالي تطلب الأمر وجود أداتين احدهما لقياس متغير الرسوب والآخر لقياس

$$
\text { المبحث الرابع }
$$

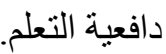

\section{عرض النتائج ومقارنتها}

1- 1 التعرف على مستوى الرسوب لاى طالبات الثالث متوسط.

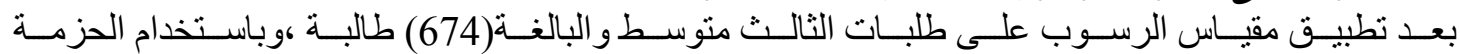

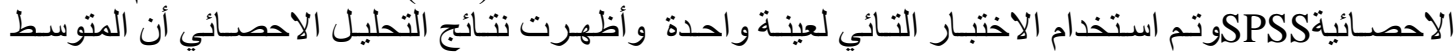

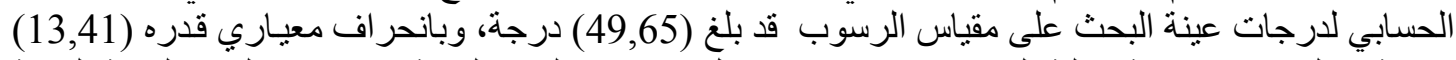

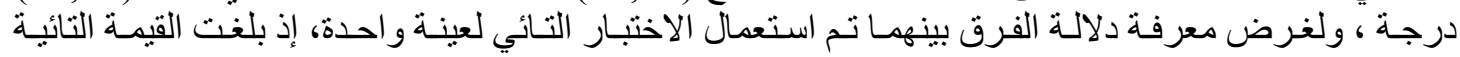

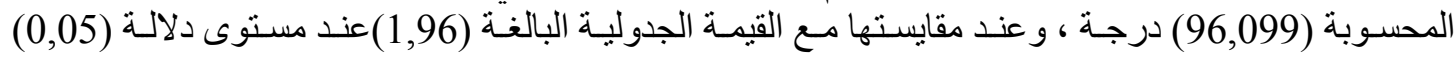

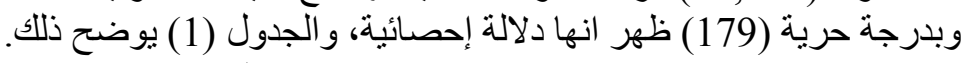

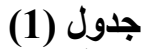

يوضح المتوسط الحسابي والانحراف المعياري والقيمة التائية المحسوبة والجدولية لعينة الطلبات على مقياس

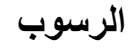

\begin{tabular}{|c|c|c|c|c|c|c|}
\hline \multirow{2}{*}{ الاحصالةية } & \multirow{2}{*}{ |الدلالة } & \multicolumn{2}{|c|}{ القيمة التائية } & \multirow{2}{*}{ المعياري } & \multirow{2}{*}{ |الحستوسبي } & \multirow{2}{*}{ | علاد } \\
\hline & & الجدولية & المحسوبة & & & \\
\hline دالة & 0,05 & $\overline{1,96}$ & $\overline{96,09}$ & $\overline{13,41}$ & 49,65 & 674 \\
\hline
\end{tabular}




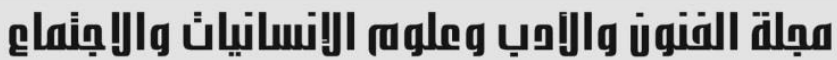

Journal of Arts, Literature, Humanities and Social Sciences www.jalhss.com

حيث يتضح من الجدول اعلاه ان الرسوب دال ومن هذا يتضـح ان هنـاك امور عديدة لرسوب الطالبـات وفثلـهن

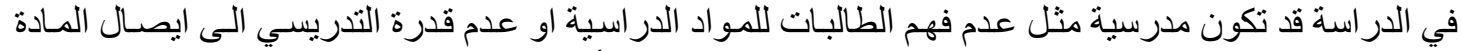

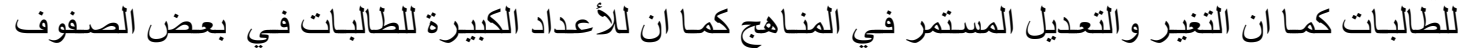

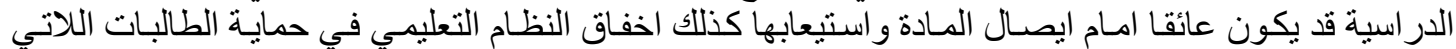

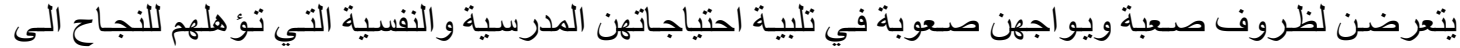
صفوف اعلى.

2- التعرف على مستوى الدافعية للتعلم لاى طالبات الثالث متوسط.

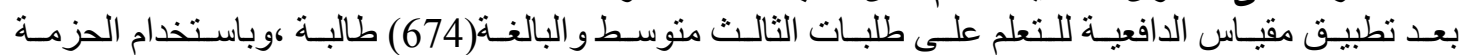

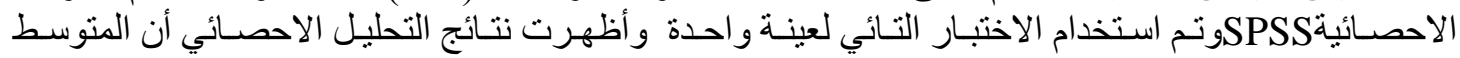

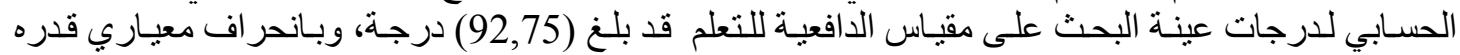

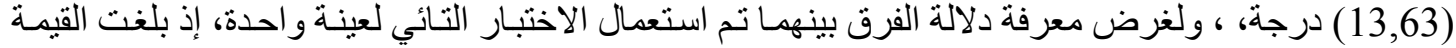

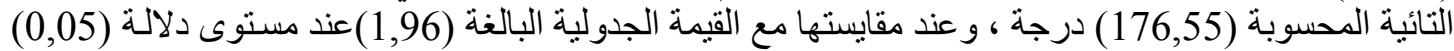
وبدرجة حرية (179) ظهر انها دلالة إحصائية، والجدول (2) ئلينة يوضح ذللك.

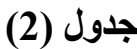

يوضح المتوسط الحسابي والاتحراف المعياري والقيمة التائية المحسوبة والجدولية لعينة الطلبات على مقياس الافعية للتعلم

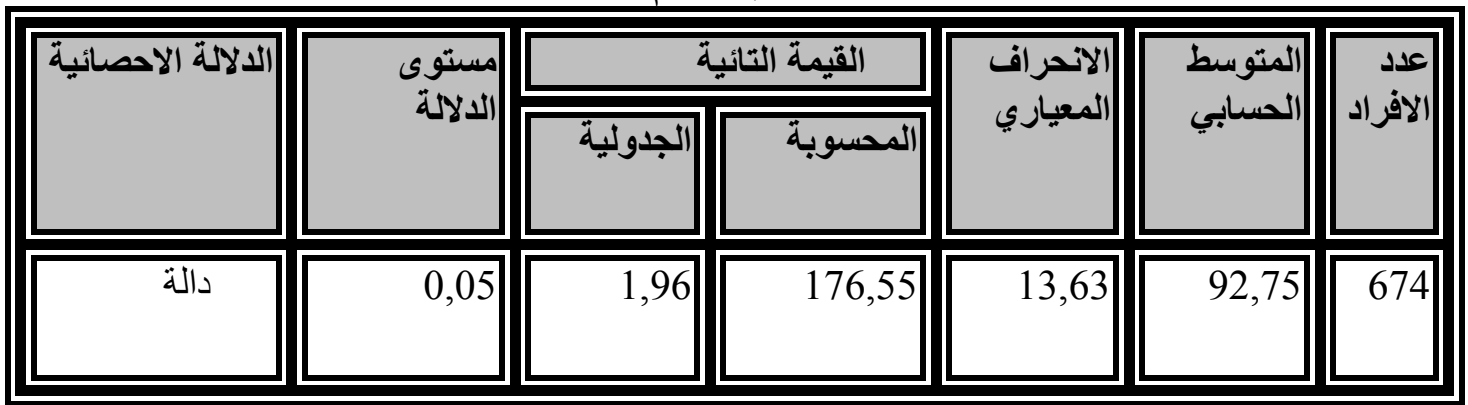

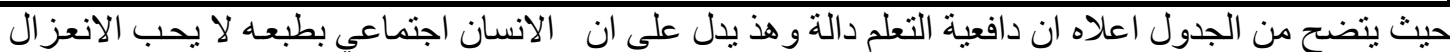

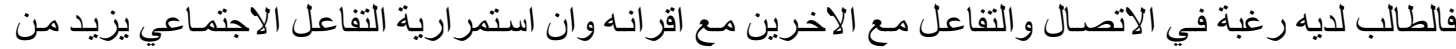

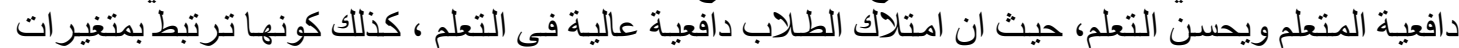

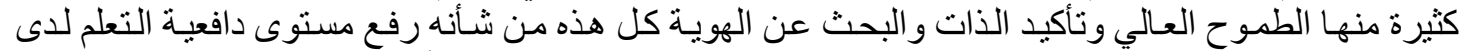
الافر اد، حيث يرى الفرد ان النجاح و الحصول على درجات عالية هو جزء هن من تأكيد ذاته وحريته.

3ـ العلاقة بين الرسوب ودافعية التعلم لاى طالبات الثالث

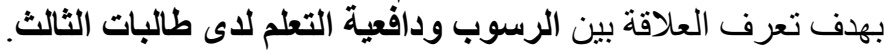

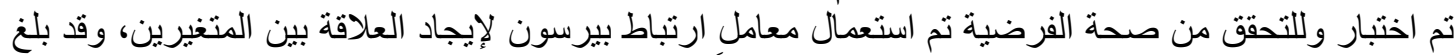

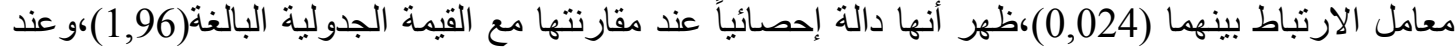

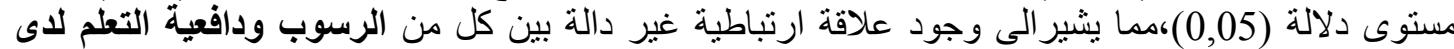

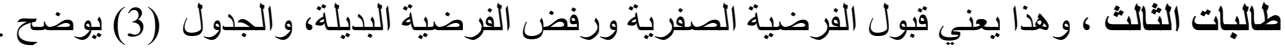




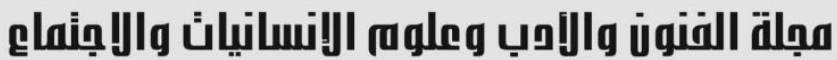

Journal of Arts, Literature, Humanities and Social Sciences www.jalhss.com

Volume (62) December 2020

العدد (62) ديسمبر 2020

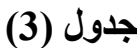

معامل ارتباط بيرسون والاختبار التائية لمعنوية معامل ارتباط بيرسون بين الرسوب ودافعية التعلم لدى طالبات الثالث الث

\begin{tabular}{|c|c|c|c|c|}
\hline النتيجة الاحصائية & مستوى الدلالة & الجدولية & قيمة معامل ارتباط بين الرسوبة التعلم & العراد \\
\hline غير دالة & 0,05 & 1,96 & 0,024 & 674 \\
\hline
\end{tabular}

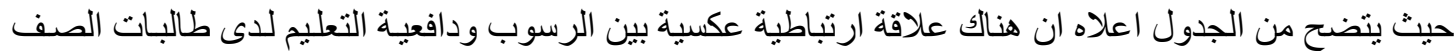

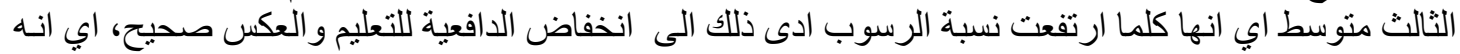

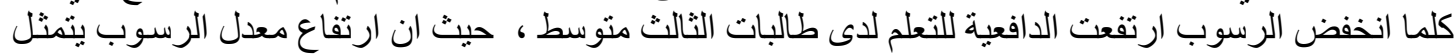

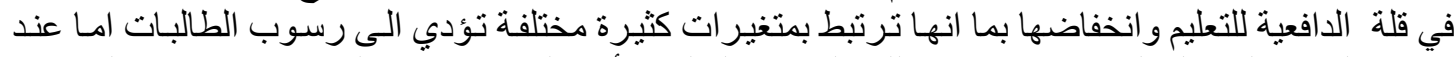

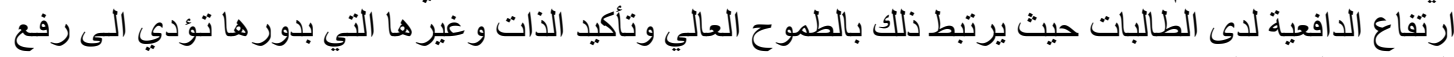

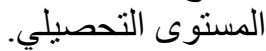

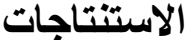

حيث ان هناك عدد من الاستنتاجات لهذا البحث وهي كالاتي:

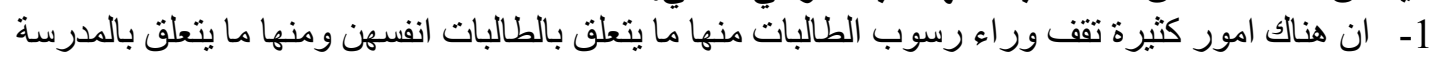

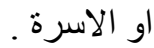
2- ملة او انقطاع التو اصل بين البيت و المدرسة. 3- صعوبة المناهج الدر اسية واستصعباها من قبل الطالبات.

التوصيات

1- - التكر ار للمادة التعليمة في الصف لان الت هنالك فروق فردية بين الطالبات يجب مر اعاتها.

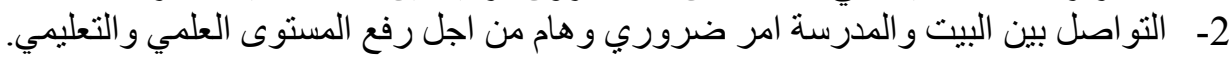

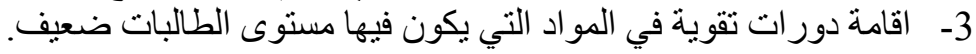

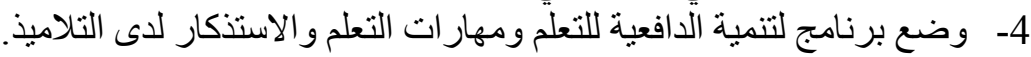
5- تدريب التلاميذ على استنباط الجو انب المهمة من المنهاج الدر اسي وتدريبهم على حل المشكلات.

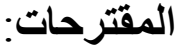
1- اقامة در اسة عن الرسوب او الخفاض المستوى التحصيلي لفئات عمرية اخرى.

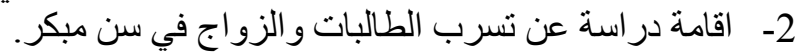

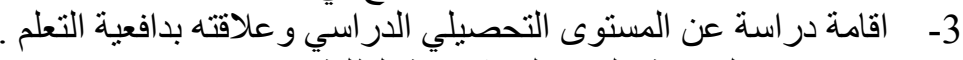
4- اجر اء نفس الدر اسة ولكن على شريحة الطلبة.

\section{المصادر}

1- الابر اشي، محمد عطية.(1986).التربية الاسلامية وفلاسفتها ،دار احياء الكتب العربية، مصر.

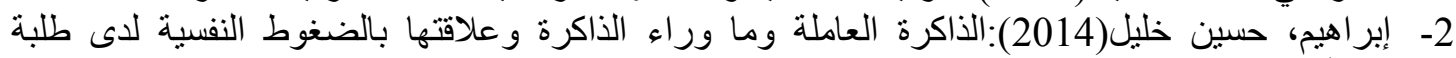

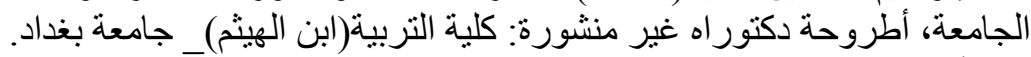

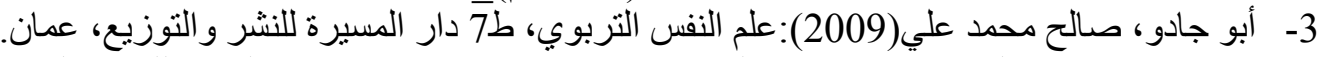

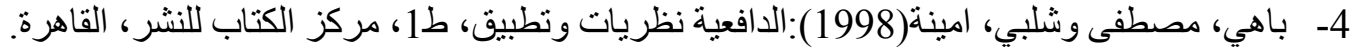
5- بديوي، زينب عبد العليم.(1992). الفروق في المكونات المعرفية والاستر اتيجية حل المشكلات الكيميائية 


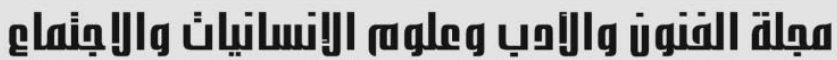

Journal of Arts, Literature, Humanities and Social Sciences www.jalhss.com

مرتفعي ومنخفضي الاداء، رسالة دكتور اه غير منشورة، كلية التربية ، جامعة قناة السويس.

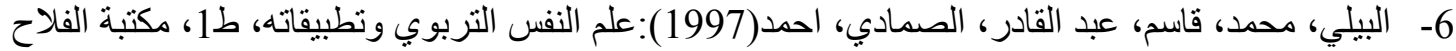
للنشر والتوزيع، الامار ات العربية المدافية المتحدة. 7- حدة، لوناس(2012): علاع، الافئة التحصبل الدراسي بدافعية التعلم لدى المراهق المتمدرس، رسالة ماجستير

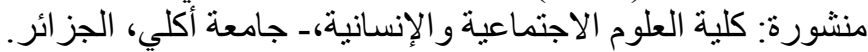

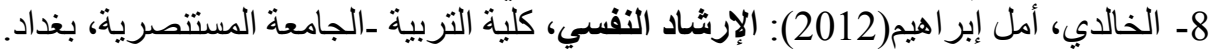

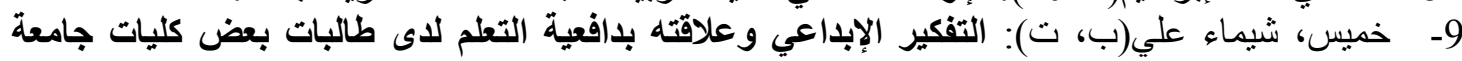

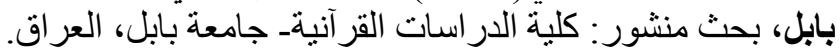

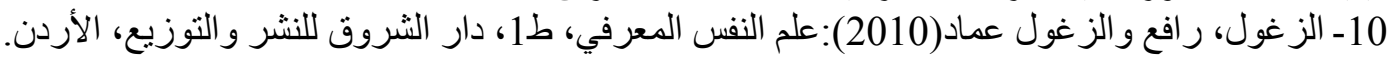

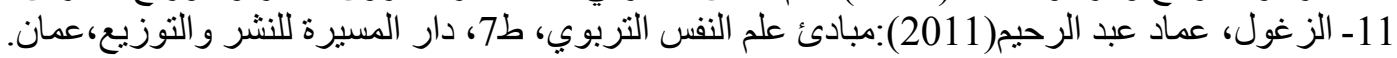
12- الطريحي، فاهم وحسين ربيع حمادي(2012):مبادئ في علم النفس التربوي، ط1، طاري، دار صفاء للنشر

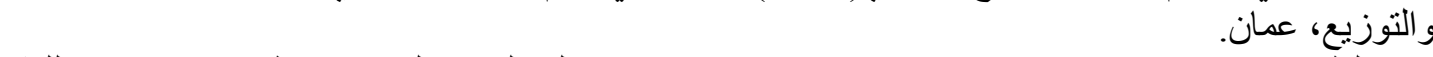
13- الطريحي، فاهم وحسين ربيع حمادي(2012):مبادئ في علم النفس التربوي، ط1، دار صفاء للنشر و التوزيع، عمان.

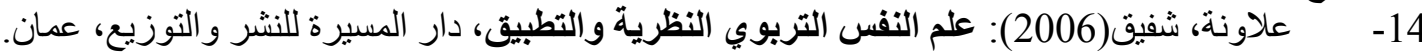

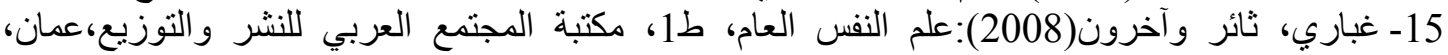

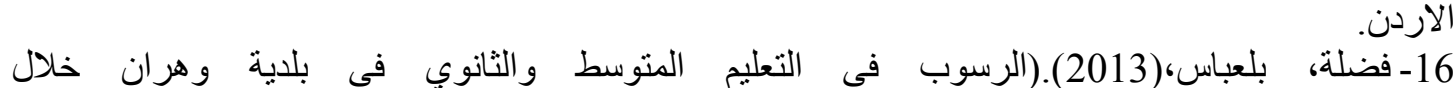

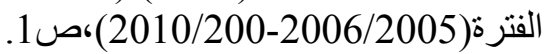

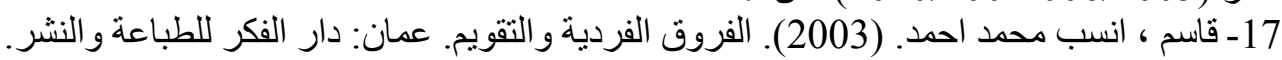

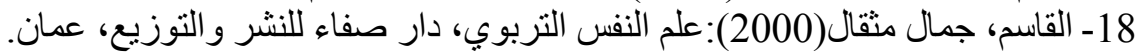

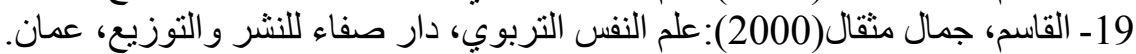

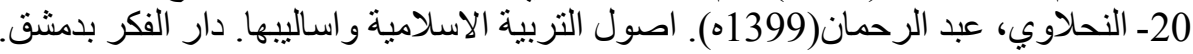

1. Cohen, J.(1969). Personality assessment, Chicago: R and McNally\& Company.

2. Coninn, F.(1997). Motivation to learn. University of saskatchwen, www.asask.ca/educatio

3. Houston, J. P. (1985). Motivation. New York: Macmillan publishing company.

4. Murphy, G(1947). Personalty: Abiosocial approach to origins and structure. New York: ltarper\& Craw.

5. Ormrod,J.(1995). Educational Psychology: Principles and Application. New York: Merill.

6. Owen, S.V. Forman, R.D.\& Moscow. H.(1981). Educational Psychology: An introduction. ( $\left.2^{\text {nd }} \mathrm{ed}\right)$.

7. Wlodkowski, R.(1991). Strategies to enhance adult motivation to learn. Nebraska institule for the study of adult literacy.

8. Woolfolk, A. (1987). Educational Psychology ( $3^{\text {rd }}$ ed). Englewood Cliffs, NJ: Prentice-Hall. 